\title{
Оценка эффективности комбинированного применения способов профилактики несостоятельности швов кишечных анастомозов
}

\author{
Э. К. Агаев, 3. Э. Исмайылова, Т. Э. Мамедов \\ Азербайджанский медицинский университет, г. Баку, Республика Азербайджан

\section{Estimation of efficacy of combined application of prophylactic methods for insufficiency of the intestinal anastomoses sutures}

\author{
E. K. Aghayev, Z. E. Ismayilova, T. E. Mamedov \\ Azerbaijani Medical University, Baku, Republic of Azerbaijan
}

\section{Реферат}

Цель. Изучение эффективности комбинации различных способов профилактики несостоятельности швов кишечных анастомозов (НШКА) у больных после плановой, экстренной и неотложной резекции различных сегментов кишечника. Материалы и методы. Изучено результаты лечения 642 больных, которым выполнена резекция различных сегментов тонкой и толстой кишок с наложением первичных анастомозов. Из 642 больных 357 (55,6\%) оперированы в плановом порядке, 285 (44,4\%) - по неотложным и экстренным показаниям. У 467 (72,7\%) больных наложены анастомозы по типу бок в бок, у 150 (23,4\%) - по типу конец в конец, у 25 (3,8\%) - по типу конец в бок. С целью профилактики НШКА выполняли перманентную внутрибрыжеечную блокаду, проводили лимфотропную терапию, местную лазеромагнитотерапию, интубационную декомпрессию, санацию и гастроэнтеросорбцию с полифепаном, а также внутримышечно вводили человеческий плацентарный гидролизат «Laennec».

Результаты. НШКА наблюдали у 10 (1,6\%) больных: у 6 (4,0\%) - с анастомозами конец в конец и у 4 (0,86\%) - с анастомозами бок в бок. Несостоятельными были 1 (10\%) тонко-толстокишечный анастомо3, 2 (20\%) тонко-тонкокишечных и 7 (70\%) толсто-толстокишечных анастомозов.

Выводы. С целью профилактики НШКА у больных, оперированных в неотложном, экстренном и плановом порядке рекомендуется использовать по показаниям перманентную внутрибрыжеечную (забрюшинную) блокаду с лимфотропной терапией, местную лазеромагнитотерапию, интубационную декомпрессию, санацию и гастроэнтеросорбцию с полифепаном, а также препарат «Laennec».

ключевые слова: резекция кишечника; несостоятельность швов анастомоза; плацентарный гидролизат; профилактика. Abstract

Objective. Studying of efficacy and combination of different prophylactic methods for insufficiency of the intestinal anastomoses sutures (IIAS) in the patients after elective, urgent and emergent resection of various intestinal segments.

Materials and methods. There were studied the results of treatment of 642 patients, in whom resection of various segments of small and large bowel with formation of primary anastomoses was performed. Of 642 patients 357 (55.6\%) were operated in elective order, 285 (44.4\%) - in accordance to urgent and emergent indications. In 467 (72.7\%) patients the anastomoses were formatted in side-to-side fashion, in 150 (23.4\%) - the end-to-end, in 25 (3.8\%) - the end-to-side. Permanent intramesenterial (retroperitoneal) blockades were performed, the lymphotropic therapy, local laseromagnet therapy, the intubation decompression, sanation and gastroenterosorption with polyphepan, as well as the human placental hydrolysate «Laennec» preparation, injected intramuscularly, were conducted for the IIAS prophylaxis.

Results. IIAS was observed in 10 (1.6\%) patients: in 6 (4.0\%) - with anastomoses end-to-end and in 4 (0.86\%) - with anastomoses side-to-side. There were insufficient 1 (10\%) anastomosis between the small and large bowel, $2(20 \%)$ - between parts of the small bowel and 7 (70\%) - between parts of a large bowel.

Conclusion. Permanent intramesenterial (retroperitoneal) blockade with lymphotropic therapy, local laseromagnet therapy, the intubation decompression, sanation and gastroenterosorption with polyphepan, as well as «Laennec» preparation are recommended in accordance to indications for the IIAS prophylaxis in patients, operated in emergent, urgent and elective order.

Key words: intestinal resection; insufficiency of the anastomoses sutures; placental hydrolysate; prophylaxis.

Несостоятельность швов кишечных анастомозов (НШКА) является одной из актуальных проблем современной абдоминальной хирургии. Несмотря на большие достижения в области кишечной хирургии, внедрение современных механических сшивающих аппаратов, а также микрохирургической и атравматической методики соединения тканей, частота возникновения НШКА, по данным различных авторов, составляет 1 - 19\% $[1,2]$.
Проблема более актуальна у больных после неотложной и экстренной резекции кишечника на фоне распространенного перитонита (РП), острой кишечной непроходимости (ОКН) и раковой интоксикации [3]. Среди причин возникновения данного осложнения - ишемия анастомозируемых кишечных сегментов, повышение внутрикишечного давления, инфицирование шовной полосы анастомоза, технические погрешности, наличие у боль- 
ных сахарного диабета, а также злокачественного новообразования и его распространенности, радио- и химиотерапия до операции и др. [4, 5].

С целью прогнозирования возникновения НШКА предложено множество способов, таких как лазерная и ультразвуковая допплерография, интраоперационная флуоресцентная ангиография (при лапароскопических операциях), контактная биомикроскопия, электромиография, трансиллюминационная ангиотензиометрия, пульсомоторография и др. [6, 7].

Для профилактики НШКА применяют различные методы и средства: укрепление кишечных швов фибрин-коллагеновой субстанцией [8] и гемостатиком «TachoSil» [9], применение фибринового клея [10] и биоклея [11], укрепление зоны анастомоза дополнительными швами [12], локальное применение мезенхимальных стволовых клеток в зоне анастомоза [13, 14], интубационная декомпрессия, санация и гастроэнтеросорбция, лазеромагнитотерапия зоны анастомоза, перманентная внутрибрыжеечная (забрюшинная) блокада и лимфотропная терапия [15].

Цель исследования: изучение эффективности комбинации различных способов профилактики НШКА у больных после плановой, экстренной и неотложной резекции различных сегментов кишечника.

\section{Материалы и методы исследования}

Нами проведено клиническое наблюдение 642 больных после резекции различных сегментов тонкой и толстой кишок с наложением первичных анастомозов в период с 1990 по 2019 г. У 285 (44,4\%) из 642 больных операции выполнены в неотложном и экстренном порядке по поводу осложненных форм раковой опухоли, острой кишечной непроходимости (ОКН) различной этиологии, распространенного перитонита (РП), открытых и закрытых повреждений кишечника, тромбоза и тромбоэмболии брыжеечных сосудов, у 357 (55,6\%) - в плановом порядке по поводу неосложненной раковой опухоли тонкой и толстой кишок, долихосигмы и мегадолихоколона, осложненного хроническим запором, требующим регулярного применения слабительных, неспецифического язвенного колита, тотального полипоза, распространенного дивертикулеза с симптомами дивертикулита и др.

Из 642 больных толсто-толстокишечные анастомозы сформированы у 354 (55,1\%), тонко-толстокишечные - у 156 (24,3\%), тонко-тонкокишечные - у 132 (20,6\%). У 467 (72,7\%) больных анастомозы наложены по типу бок в бок, у 150 (23,4\%) - по типу конец в конец, у 25 (3,8\%) - по типу конец в бок в основном ручным способом с использованием только атравматических игл с рассасывающейся ниткой 3/0 и 4/0. Только у 47 (7,3\%) больных при наложении анастомозов нами были использованы циркулярные степлеры. Эти больные были оперированы в основном по поводу рака левой половины толстой кишки, и у них возникла необходимость соединения низведенной толстой кишки с низкоампулярным отделом прямой кишки. У 53 (8,3\%) больных резекция различных сегментов ки- шечника была выполнена лапароскопическим путем. Из них у 21 (39,6\%) больного анастомозы были наложены интракорпорально циркулярным сшивающим аппаратом.

С целью определения жизнеспособности резецированных сегментов кишечника и прогнозирования возникновения НШКА нами были использованы методы трансиллюминационной ангиотензиометрии и пульсомоторографии по М. 3. Сигалу и 3. М. Сигалу.

Для профилактики несостоятельности швов кишечных анастомозов проводили перманентную внутрибрыжеечную блокаду и лимфотропную терапию (у 145 больных), местную лазеромагнитотерапию (у 162), интубационную декомпрессию, санацию и гастроэнтеросорбцию с полифепаном (у 202) и терапию внутримышечным введением человеческого плацентарного гидролизата «Laennec» (у 68).

У 145 (22,6\%) больных с тонко-тонкокишечными и тонко-толстокишечными анастомозами выполнена перманентная внутрибрыжеечная (забрюшинная) блокада и проведена лимфотропная терапия. Для этого после завершения основного этапа операции и санации брюшной полости вводили раствор новокаина в корень брыжейки тонкой кишки, затем выполняли надрез над набухшим новокаиновым инфильтратом длиной 0,5 см, после чего артериальным зажимом тупо расширяли и углубляли рану в виде туннеля и вводили тонкий (диаметр 1 мм) катетер, который фиксировали к листкам париетальной брюшины кетгутовыми швами (№ 4/0). После герметизации дефекта раны париетальной брюшины дистальную часть катетера выводили через рану и пришивали к коже. По завершении операции начинали перманентную внутрибрыжеечную блокаду и лимфотропную терапию через катетер лекарственным составом, включающим местный анестетик - 0,5\% раствор новокаина (по 7 мл/кг/сут), антикоагулянт - гепарин (по 150 ЕД/кг/сут), антихолинэстеразный препарат - прозерин (по 0,03 мг/кг/сут) и антибиотик - цефтриаксон (по 15 мг/кг/сут). Для получения эффекта перманентной внутрибрыжеечной блокады инфузию проводили 4 - 6 раз в день. Раствор вводили капельно (со скоростью 100 - 120 капель за 1 мин) в объеме 60 - 80 мл при каждой инфузии.

У 202 (31,5\%) больных после неотложной и экстренной резекции кишечника с целью интраоперационной и послеоперационной декомпрессии, санации и гастроэнтеросорбции выполнили назоинтестинальную (у 123), трансанальную (у 52) или комбинированную (у 27) интубацию пищевого канала стандартными силиконовыми зондами № 25 и 33. Для гастроэнтеросорбции использовали полифепан. Он положительно влияет на перистальтику кишечника, оказывает адсорбирующее, детоксикационное, антиоксидантное действие, повышает фагоцитарную активность ретикулоэндотелиальной системы, снижает протромбиновый индекс, повышает концентрацию иммуноглобулина А, ускоряет репаративные процессы, стимулирует регенерацию. Сеансы гастроэнтеросорбции проводили 3 - 4 раза в день. 
Для профилактики НШКА у 162 (25,2\%) больных проводили также лазеромагнитное облучение области швов анастомоза во время операции и в послеоперационном периоде, что способствует улучшению микроциркуляции, ликвидации отека в тканевом шовном валике и первичному заживлению кишечных анастомозов.

В последние годы с целью профилактики НШКА мы используем человеческий плацентарный гидролизат «Laennec», после его апробации с помощью экспериментальных исследований. Препарат вводили внутримышечно в дозе $2-4$ мл $1-2$ раза в день в течение 7 - 10 дней после операции. Нами в эксперименте доказано, что препарат «Laennec» усиливает регенерацию и ангиогенез в зоне анастомоза, а также, уравновешивая процесс синтеза и лизиса коллагена, способствует его более прочному образованию.

\section{Результаты}

НШКА наблюдали у 10 (1,6\%) больных, анастомозы у которых в основном были наложены на фоне ОКН и РП (у 9). Только у 1 (0,28\%) больного, оперированного в плановом порядке, у которого был наложен тонко-толстокишечный анастомоз после субтотальной колэктомии по поводу тотального полипоза, наблюдали НШКА. Несостоятельными были 1 (10\%) тонко-толстокишечный анастомоз, 2 (20\%) тонко-тонкокишечных и 7 (70\%) толсто-толстокишечных анастомозов. У 53 больных, оперированных лапароскопическим путем с наложением ручного экстракорпорального (n=32) и степлерного интракорпорального (n=21) анастомоза, НШКА не наблюдали.

Сравнительным анализом выяснили, что НШКА возникала в основном у больных с анастомозами по типу конец в конец. НШКА наблюдали лишь у 4 (0,86\%) из 467 больных с анастомозами по типу бок в бок и у 6 (4,0\%) из 150 больных с анастомозами по типу конец в конец.

\section{Обсуждение}

Внедрение комплексных методов профилактики НШКА у наблюдаемых больных позволило получить весьма удовлетворительные результаты, что связано с поддержкой положительных и блокадой отрицательных факторов, влияющих на регенерацию кишечных анастомозов. Применение предложенного нами способа перманентной внутрибрыжеечной блокады и лимфотропной терапии блокировало патологическую симпатическую и болевую импульсацию, в результате чего исчезал спазм илеоцекального сфинктера, стенок кишечника и регионарных сосудов, значительно уменьшалась боль в брюшной полости. Неспазмированный илеоцекальный сфинктер и ускорение перистальтической активности обеспечивали синхронный пассаж химуса в толстую кишку, предупреждая повышение внутрипросветного давления в тонкой кишке, что благоприятно влияло на заживление тонкокишечных анастомозов.

Доказано, что после ревизии и санации брюшной полости бактериальная обсемененность центральной лимфы резко возрастает [13], а на фоне перитонита и кишечной непроходимости это приобретает еще более тяжелый характер. Забрюшинное введение антибиотика широкого спектра действия при таких обстоятельствах дает эффект лимфотропной антибиотикотерапии, который приводит к уменьшению гнойно-септических осложнений. Кроме того, введением гепарина в корень брыжейки тонкой кишки в составе инфузата улучшает крово-и лимфообращение кишечной стенки, в том числе шовной полосы анастомоза. Улучшение венозного оттока и лимфодренажа способствует уменьшению отека в тканевом шовном валике, что усиливает процессы регенерации и первичного заживления кишечных анастомозов.

После перманентной забрюшинной новокаиновой блокады у больных наблюдали ускорение (1 - 2 сут) восстановления кишечной перистальтики. Это, с одной стороны, связано с блокадой патологической симпатической импульсации, а с другой - с воздействием прозерина, который вводили в корень брыжейки тонкой кишки в составе инфузата. Усиление перистальтической активности кишечника способствует раннему отхождению газов и высвобождению кишечного содержимого, в результате чего уменышается внутрипросветное давление, являющееся одной из основных причин нарушения интрамуральной гемодинамики и возникновения НШКА. Кроме того, прозерин усиливает интрамуральную гемодинамику, чем положительно влияет на заживление кишечных анастомозов.

Местная лазеромагнитотерапия во время операции и в послеоперационном периоде тоже имела положительное влияние на процесс заживления анастомозов, приводя к улучшению микроциркуляции и ликвидации отека в тканевом шовном валике, что способствовало первичному заживлению кишечных анастомозов.

Положительный эффект интубационной декомпрессии, санации и гастроэнтеросорбции с полифепаном на процесс заживления кишечных анастомозов проявился в основном за счет понижения внутрикишечного давления. Кроме того, применение полифепана, разведенного физиологическим раствором, улучшало перистальтику кишечника, проявляло адсорбирующее, детоксикационное, антиоксидантное действие, повышало фагоцитарную активность ретикулоэндотелиальной системы, снижало протромбиновый индекс, повышало концентрацию иммуноглобулина А, ускоряло репаративные процессы, стимулировало регенерацию. В последние годы мы очень редко используем интубационную декомпрессию пищеварительного канала из-за ее травматичности и непереносимости больными.

С начала 2018 г. с целью ускорения процесса заживления кишечных анастомозов и профилактики НШКА мы используем в клинической практике (после проведенных экспериментов в 2017 г.) инъекционный лекарственный препарат - гидролизат плаценты человека «Laennec». В эксперименте нами доказано, что при внутримышечном введении гидролизата плаценты человека в шовной по- 
лосе анастомоза повышается митозный индекс, происходит уплотнение крипт и коллагеновых волокон, становится более интенсивный микроангиогенез. Была отмечена хорошая сохранность местных регуляторов моторно-эвакуаторной функции стенки анастомоза - интрамуральных вегетативных нервных стволов. Применение данного препарата способствовало появлению равновесия в процессах фибриллогенеза и фибриллолизиса, а также сохранению мышечной прослойки, обеспечивающей моторно-эвакуаторную функцию на оптимальном морфофункциональном уровне. Основной эффект этого препарата - регенераторный за счет многочисленных факторов роста, в том числе FGF (Fibroblast Growth Factor), под влиянием которого усиливается синтез коллагена и эластина в зоне анастомоза, что является одним из основных факторов заживления кишечных анастомозов. Удовлетворительные результаты экспериментальных исследований побудили нас применять препарат «Laennec» с целью профилактики НШКА.

\section{Выводы}

Для профилактики НШКА у больных, оперированных в неотложном, экстренном и плановом порядке, рекомендуется использовать по показаниям перманентную внутрибрыжеечную (забрюшинную) блокаду с лимфотропной терапией, местную лазеромагнитотерапию, интубационную декомпрессию, санацию и гастроэнтеросорбцию с полифепаном и препарат «Laennec». Комбинированное применение этих способов профилактики НШКА более актуально у больных с высоким риском возникновения этого осложнения после неотложной и экстренной резекции кишечника на фоне ОКН и РП.

\section{Подтверждение}

Финансирование. За счет авторов.

Информация об участии авторов. Агаев Э. К. - клинические исследования, анализ данных; Мамедов Т. Э. экспериментальные исследования, сбор и обработка данных; Исмайылова 3. Э. - дизайн статыи и перевод текста.

Конфликт интересов. Авторы декларируют отсутствие конфликта интересов.

Согласие на публикацию. Все авторы дали согласие на публикацию данной рукописи.

\section{References}

1. Chambers WM, Mortensen NJ. Postoperative leakage and abscess formation after colorectal surgery. Best Practice Research Clinical Gastroenterol. 2004;8(5):865-80.doi.org/10.1016/j.bpg.2004.06. 026.

2. Turrentine FE, Denlinger CE, Simpson VB. Morbidity, mortality, cost, and survival estimates of gastrointestinal anastomotic leaks. J Am Coll Surg. 2015;220(2):195-206. /doi.org/10.1016/j.jamcollsurg. 2014. 11.002.

3. Phillips B. Reducing gastrointestinal anastomotic leak rates: review of challenges and solutions. J Open Access Surgery. 2016;9:5-14. doi. org/10.2147/oas.s54936.

4. Fujita F, Torashima Y, Kuroki T, Eguchi S. The risk factors and predictive factors for anastomotic leakage after resection for colorectal cancer: reappraisal of the literature. Surg Today 2014; 44(9):1595-602. doi org/10.1007/s00595-013-0685-3.

5. Kruschewski M, Rieger H, Pohlen U. Risk factors for clinical anas-tomotic leakage and postoperative mortality in elective surgery for rectal cancer. Int J Colorectal Dis. 2007;22(8):919-27. doi.org/10.1007/ s00384-006-0260-0.

6. Kudszus S, Roesel C, Schachtrupp A, Hoer J. Intraoperative laser fluorescense angiography in colorectal surgery: a noninvasive analysis to reduce the rate of anastomotic leakage. Langenbecks Arch Surg. 2010;395(8):1025-30. doi.org/10.1007/s00423-010-0699-x.

7. Fouda E, El Nakeeb A, Magdy A, Hammad E, Othman G, Farid M. Early detection of anastomotic leakage after elective low anterior resection. J Gastrointest Surg. 2011;15(1):137-44. doi.org/10.1007/s11605010-1364-y.

8. Suarez-Grau J, Garcia C, Franco C, Ruis C, Durantes F, Conde S, et al. Fibrinogen-thrombin collagen patch reinforcement of high-risk colonic anastomoses in rats. World J Gastrointest Surg. 2016;8(9):627-633. doi.org/10.4240/wjgs/v8.i9.627.

9. Garcia-Vasquez C, Gomez-Garcia S, Pastor Idoate C, De Pablo D, Ferandez-Acenero MJ. Histopathological changes associated to an absorbable fibrin patch (Tachosil $\left.{ }^{\circledR}\right)$ covering in an experimental model of high-risk colonic anastomoses. Histol Histopathol. 2018;33(3):299 306. doi: 10.14670/HH-11-930.

10. Wang P, Wang J, Zhang W, Li Y, Li J. Effect of the combination of fibrin glue and growth hormone on intestinal anastomoses in a pig model of traumatic shock associated with peritonitis. World J Surg. 2009;33(3):567-76. doi.org/10.1007/s00268-008-9889-x.

11. Hoeppner J, Willa K, Timme S, Tittelbach-Helmrich D, Hopt UT, Keck $\mathrm{T}$, et al. Reinforcement of Colonic Anastomoses with a Collagenous Double-Layer Matrix Extracted from Porcine Dermis. Eur Surg Res. 2010;45(2):68-76. /doi.org/10.1159/000318856.

12. Kim IY, Kim BR, Kim YW. Applying reinforcing sutures to stapled colorectal anastomosis after low anterior resection for rectal cancer. Eur J Surg Oncol. 2015;41(6):808-9. doi: 10.1016/j.ejso.2015.03.230.

13. Caziuc A, Calin Dindelegan G, Pall E, Mironiuc A. Stem cells improve the quality of colonic anastomoses - A systematic review. J BUON. 2015;20(6):1624-9. PMID:2685442.

14. Adas G, Arikan S, Karatepe O, Kemik O, Ayhan S, Karaoz E, et al. Mesenchymal stem cells improve the healing of ischemic colonic anastomoses (experimental study). Langenbecks Arch Surg. 2011;396(1):115-26. doi: $10.1007 /$ s00423-010-0717-z.

15. Aghayev EK, Cafarov CM, Bagirov QS. The way to prevent incompetence of sutures of intestinal anastomosis. Bulleten Evraziyskoqo Patentnoqo vedomstvo. 2010;(2):86. No 015637.

Надійшла28.05.19 